\title{
POETRY
}

\section{At the window}

Previously published at www.cmaj.ca

"ALS won't kill you, the loneliness will"

$$
\text { - Erin Brady Worsham }
$$

Clumsiness was the robin, a harbinger hopping through the snow. Always worn out and tired, I just thought work was consuming, sleep never quite enough. Then lids of jars became recalcitrant, even when already opened before.

After my disease had a name, I became a teaching tool. Lying still, new doctors looking me over,

तิ checking my reflexes,

긍 or how I work to breathe.

Loneliness is the hardest part.

Air hisses in and out through

blue and white accordion tubing, my body in its cradle,

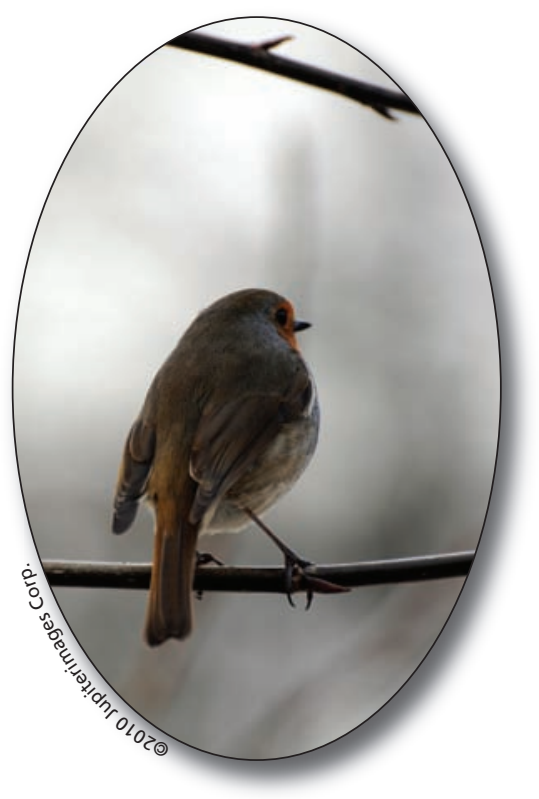

warmed and humidified.

I learn a new rhythm, a dance that has become my life, hereafter marked by whoosh and chime and beep of my dutiful machines.

Dying would be easy. Just take my handmaiden away. But I don't plan on leaving anytime soon. These machines, this body. My mind.

That's still me, chasing after that bird, through the melting snow.

\section{Wynne Morrison MD MBE}

Critical care

The Children's Hospital of Philadelphia Philadelphia, USA 